\title{
CISPRVETET \\ PERFIL DOS TUTORES PARTICIPANTES DO PROGRAMA DE MICROCHIPAGEM E ESTERILIZAÇÃO CIRÚRGICA NO MUNICÍPIO DE SÃO JOÃO DA BOA VISTA - SP
}

\author{
Congresso Iberoamericano de Saúde Pública Veterinária, 3a edição, de 31/08/2021 a 03/09/2021 \\ ISBN dos Anais: 978-65-89908-81-4
}

SCARPIONI; Lorena Bueno ${ }^{1}$, MANÇANARES; Celina de Almeida Furlanetto Mançanares ${ }^{2}$

\section{RESUMO}

O grande crescimento de cães e gatos errantes nos centros urbanos, tem gerado um problema de saúde pública, podendo causar até mesmo acidentes de trânsito, mordeduras a população, contaminação do ambiente e transmissão de doenças. Isso está relacionado à falta de conscientização da população sobre tutela responsável de cães e gatos, e consequentemente a exacerbada procriação desses animais (GARCIA, 2005). Muitos tutores não possuem conhecimento sobre seus animais, com isso a deficiência do vínculo entre o ser humano e seu animal é gerada, levando uma irresponsável tutela e consequentemente ao abandono. Podemos afirmar que o efeito que o abandono de animais exerce sobre a saúde pública está relacionado à escassez de conduta e posturas de posse e guarda responsável de cães e gatos (GARCIA, 2005). Aspectos sociais como níveis educacionais e saneamento básico baixos, relacionadas à escassez de consciência sanitária da população e à negligência do poder público resultam em um grande quantitativo de cães não domiciliados, que vivem livremente pelas ruas. (MOUTINHO; NASCIMENTO; PAIXÃO, 2015). O Programa de Controle Populacional de Cães e Gatos da Prefeitura de São João da Boa Vista, no estado de São Paulo, foi instituído em julho de 2019. O Serviço de Controle Animal é um setor do Departamento de Meio Ambiente, Agricultura e Abastecimento da Prefeitura Municipal, responsável pelos cadastramentos, microchipagem e agendamentos das esterilizações cirúrgicas de cães e gatos que ocorrem no Hospital Veterinário da Fundação de Ensino Dr. Octávio Bastos Unifeob. Para esta pesquisa, 282 tutores de cães e gatos cadastrados no Programa de Microchipagem e Esterilização Cirúrgica da Prefeitura Municipal de São João da Boa Vista-SP, foram entrevistados através de um questionário com 18 perguntas. As entrevistas foram realizadas presencialmente, no dia da microchipagem dos animais no Setor. Os tutores foram questionados sobre a autorização da participação da pesquisa antes das entrevistas e para realização deste estudo foram respeitados todos os parâmetros Internacionais da bioética e bem estar humano, conforme preconiza CONEP (Comissão Nacional de Ética em Pesquisa) e CEP - Comissão de Ética da Faculdade de Medicina Veterinária de São João da Boa Vista/ UNIFEOB. Após a microchipagem do animal as entrevistas eram feitas e a data da esterilização cirúrgica agendada. Foi 
preenchida uma planilha no Microsoft Excel ${ }^{\circledR}$ com as perguntas elaboradas pelo executor e as respostas dos tutores. Por conta da Pandemia COVID-19 as entrevistas foram realizadas esporadicamente. O questionário foi elaborado com perguntas específicas sobre Posse Responsável, a situação socioeconômica da família e o bem-estar dos animais. O objetivo do presente trabalho é avaliar a conduta e responsabilidade dos tutores em relação a seus cães e gatos, de acordo com a distribuição geográfica e de renda, analisando o impacto que esses dados exercem sobre a Posse Responsável, e consequentemente elucidar como o Serviço Público pode intervir para a melhoria de políticas públicas, que visem conscientizar a população do município sobre o assunto.

PALAVRAS-CHAVE: Cães, Gatos, Saúde pública, Posse responsável 